\title{
The Effectiveness of Utilizing Nox Android Emulator for Interactive Teaching on Students' Writing Competence and Involvement
}

\author{
Edi Pujo Basuki \\ UNUSA, Indonesia \\ ediayarga@unusa.ac.id \\ Novi Rahmania Aquariza \\ UNUSA, Indonesia \\ novirahmania@unusa.ac.id
}

\begin{abstract}
Learning English, as outlined in Curriculum 2013, is more directed at mastering the ability to write text-based genres. In this study the author introduces game by utilizing the Android Emulator. The problem of this research is to find out the effectiveness of using the Andoid Emulator tool as an effective interactive learning media on the ability to write and the involvement of students in the learning process of writing. The design of this study is pre-test-post-test group design. After implementing the Game Before Writing Procedure using the Nox Android Emulator, a post-test is performed. The population is high school students SMA Bhayangkari 10 Porong. Research samples were 39 students. The Research Instruments are tests and observation sheet. Data Analysis is using the $\mathrm{T}$ Test and descriptive. From data, the mean difference is 12,435 . This means that Learning with Game Before Writing Procedure has an influence on the ability of Writing Report.. $80 \%$ of students are actively involved in the game.

Based on the results of the T Test for the Utilization of the Nox Android Emuator in the implementation of Game Before Writing Learning Procedures, it is effective in improving report writing skills. The fun game encourages student involvement
\end{abstract}

Keywords: Nox emulator, teaching media, effectiveness

\section{Introduction}

\section{A. Background}

Commonly writing learning process is less fun than speaking, because students must concentrate on writing without interaction. Based on this consideration, an effort to make writing learning interesting requires innovation in the learning process of writing by giving students the opportunity to engage in interactive activities. One of them is to create a scenario of verbal communication activities, which allows students to interact in the target language. Games are a selection of relevant teaching procedures for that. In addition, the game procedure needs to be strengthened by the appeal of the media. And what is close to millennial students is an Android device.

For this reason, the title "The Effectiveness of Utilizing Nox Android Emulator for Interactive Teaching on Students' Writing Compentence and Involvement" was chosen, which means effectiveness of using the Android Emulator for interactive learning in writing competencies and student involvemen. 
Learning English, especially writing for high school students as outlined in Curriculum 2013, is more directed at mastering the ability to write text-based genres. The question of what needs to be mastered and how is the learning, and what is the right media, must be clear.

To gain genre-based writing skills, in addition to having to (1) master the vocabulary that is adequate for writing a text, students must (2) have the ability to compile text coherence (topics and text structure), and (3) be able to arrange sentences correctly (syntax). As for effective learning processes, approaches, strategies and teaching and learning techniques that are appropriate must be applied.

Since mastering these three elements of writing is not a simple matter, an interesting teaching and learning process is needed, namely in the form of interactive activities. Interactive learning provides greater opportunities for students to have a fun and challenging learning experience. The aim is to obtain the three elements of writing skills mentioned above through interaction between students and teacher student interactions.

In order to create interactive learning activities, one of the latest teaching language learning approaches is the Communicative Approach should be implemented. The learning methodology uses the principles of communicative methodology (Morrow, 1981), one of which is learning by doing (directly practicing).

Game (game) is one of the interactive learning procedures that is considered effective by English language educators. There are several reasons for that. First, the game is an activity that has rules, goals and elements of fun or fun (Headfield, 1990: 5). The attitude that is built through the game is relevant to the purpose of writing learning where students must have discipline, must obey the rules and have goals. What is more supportive is that the fun element can be used to offset perceptions that writing is difficult. Second, "[game] increases motivation [of students], ... which contrasts with [learning styles] which are intensive [commonly used] (Haycraft, 1978: 94). Third, the game provides an opportunity to compete in a familiar, nonhostile way so that students feel comfortable and familiar with this activity, as Lee (1979: 1) said,

"The essence of many games count on in outstripping, in a friendly fashion, someone else's performance or in bettering one's own."

In this study the author introduces game by utilizing Android devices, precisely the Android Emulator, for English learning media. There are several reasons for the choice of these devices. First, this type of gaming device has been popular, and is commonly used by the owners of these types of devices. However, there are no instructors who utilize this interesting tool as an interactive learning media. Second, how to operate is easy. Third, considering that almost all students have Android devices, this game program application can be shared with all students both for games in groups and for exercises at home as an effort of reinforcement.

Limitation of the problem to be investigated is (1) the use of the Nox Adroid Emulator tool is only for game programs as an interactive learning option, while (2) the skills to be improved are report writing competencies (more specifically writing about natural phenomena, animals). In addition to improving writing skills, (3) student involvement in the learning process is also a part of observation in this study.

\section{B. Problems}

The problem of this research is to find out the effectiveness of using the Andoid Emulator tool as an effective interactive learning media on the ability to write and the involvement of students in the learning process of writing. Specifically formulated in the following research questions: 1. Is the use of Nox Android Emulator as learning before game writing procedures effective in improving the competency of writing high school student reports? 
2. Is the utilizing the Nox Android Emulator as the effective application of game before writing learning procedures, effective in encouraging the involvement of high school studentss?

\section{C.Research Objectives}

1. To find out that the use of the Andoid Emulator for the application of game before writing learning procedures is effective in improving the competency of writing reports for high school students.

2. To find out that the use of Adroid Emulator for implementing game before writing learning procedures is effective in encouraging student involvement.

\section{Nul Hypothesis}

The use of the Nox Andoid Emulator as the application of learning before game writing procedures is not effective in improving the competency of writing of SMA Bhayangkari 3 Porong high school student reports (Ho)

\section{E. Benefits of research}

The contributions of this research are:

1. Introducing the use of Android as an interactive learning media in the form of games.

2. Introducing the game program with Nox Android Emulator.

3. Introducing Game Before Writing Learning Procedures.

4. Adding literature to learning procedures for writing through games using Andoid Emulator. Precisely, Game Learning Procedure before Writing.

\section{LITERATURE REVIEW}

The literature review for this research includes several theories related to interactive learning of foreign languages: theories about learning media, Nox Android Emelator, language learning approaches, learning methodologies, and learning procedures.

\section{A. Learning Media}

Gagne and Briggs (1974) state that Learning Media is a medium that carries messages or information intended for learning or teaching purposes. According to Paivio's dual theory (1991), information is processed through one of two channels that are generally independent. One channel processes verbal information such as text or audio. Other channel processes are non-verbal images such as illustrations and sounds in the environment.

The Nugent Study (1982) states that the highest level of learning is found when students are given information through a combination of text and images (verbal and nonverbal channels) or a combination of audio and images (verbal and nonverbal channels) compared to the same content presented through text only (verbal only). Moreover, Levie and Lentz quoted by Najjar (1982) found that the text that was accompanied by illustrations that showed what was explained in the text was better understood by children than the text that was not accompanied by illustrations.

1. Media benefits

According to Hamalik (1986), the right learning media can increase motivation, desires, interests, and excitement for students. Moreover, Arsyad Azhar (2005: 15-16) explains that the use of instructional media in the learning orientation phase will help the learning process and the effectiveness of subject delivery and content at the same time, because it also increases student motivation, interest and helps students improve understanding, to present data easily, interestingly and reliably, and solid information. Meanwhile, Dayton, and Kemp (1985: 3-4) in Arsyad Azhar (2005: 22) revealed that some of the results of the study showed the positive impact of using media as primary teaching directly. First, the delivery of lessons becomes more basic. Second, teaching can be more interesting. Third, learning to be more active in applying learning theories and principles of psychological processes that are accepted in terms of student 
participation, feedback and reinforcement. Fourth, the required teaching time can be shortened because most of the media only requires a short amount of time to convey the message and content of the lesson in a rather large amount and can be absorbed by students. Fifth, the quality of student learning can be improved if the media can communicate the teaching of the elements of knowledge in a way that is well organized, specific and clear. Sixth, learning can be given wherever and whenever desired or needed, especially if the media is designed to teach individual use. Seventh, positive attitudes towards students, what they learn, and the learning process can be improved in the end, the teacher's role can be changed in a more positive direction. Thus, instructional media provide benefits in the process of teaching and learning languages.

2. Nox Android Emulator Tool

a) What is Nox Android Emulator

On noxandroidemulator.com as the official site, it is stated that Nox App Player is a kind of Android Emulator that is liked and used by many people. This tool has so many interesting features. Nox Emulator was released in August and many users have started installing it. If people have problems with Bluestacks or other Android Emulators that people use on their computers, the Nox Android emulator for PC can be downloaded as the best android application without interruption. The experience of the Zero Android Emulator user is amazing. Nox App Player is not the only one only emulator available. There are many other Android Emulators available on the web Bluestacks, Andyroid, Youwave, Droid4x etc. All of them are quite popular. But, Bluestacks emulator is considered as the best android emulator by many users. In fact, Bluestacks is the best of all. There are some shortcomings in it. Some games cannot be played on Bluestacks emulator. But the nox player application isn't like that. It has many advanced features in it that allow people to use any type of android application.

b) Nox Android Emulator feature

This android emulator has several features, namely:

- Nox App Player is very fast and the emulator never freezes.

- Highest performance is seen with the Nox emulator.

- This App Player is designed based on Android 4.4.2 Kernel and is compatible with X86

- and AMD.

- Nox Android Emulator response speed is very fast and very stable.

- All types of games can be played on this emulator.

- Visible File Manager, Facebook Lite, Camera application

- Shaker feature is also available in this emulator.

- Google Play Store and Browser are also available on the Nox emulator.

The features in the Android Nox emulator attract more authors to choose from than other emulators.

c) Android Application

Techopedia.com states an Android application is a software application that is operated on the Android platform. Because the Android platform is designed for mobile devices, a typical Android application is designed for smart-phones or tablet PCs that are operated on Android.OS.

Still from Techopedia.com, although Android applications can be provided by developers through their website, most Android applications are uploaded and published on the Internet Android Market, an online store dedicated to this application. Android Market Features is an application both free and paid .. 
Android applications are written in the Java programming language and use the Java core library. The application was first compiled into Dalvik executables to run on the Dalvik virtual machine, which is a virtual machine specifically designed for mobile devices.

Developers can download the Android software development kit (SDK) from the Android website. The SDK includes tools, sample code, and documents that are relevant for creating Android applications.

\section{B. Interactive Learning}

Interactive learning is learning that involves participants in learning activities. In learning English, the focus is more on giving students the opportunity to use the target language. Curriculum 13 High School English has learning objectives for the achievement of productive communicative competencies (speaking and writing) and receptive (listening and reading). The goals written in the English High School Syllabus focus on mastering the functions of language and text-based genres. Considering that basic competence refers more to the competence of language functions, the Language Learning Approach applied is the Communicative Approach, which in principle the language learning process is directed at acquiring communicative competence (coomunicative competence) not just the competence of mastering elements of language elements separately. .

1. Communicative Learning Methodology

According to Keith Morrow (1981: 59) a consistent methodology is more than just a collection of learning activities or techniques. The [Foreign Language learning] methodology requires a set of principles that serve as a reference for assessing, linking, and implementing specific learning procedures, activities, or techniques.

Some principles of communicative methodology in general according to Keith Morrow are as follows.

a. Principle 1: Know what you are doing

Focus each lesson on learning how to do something. Each lesson must end with that students must clearly see that they can do something that previously could not do initially and something that must be communicatively useful. This means students are truly able to do communicative tasks in English.

b. Principle 2: the whole is more than the sum of the parts (The whole is more than just a collection of elements)

The hallmark of the communicative method is the orientation of learning above the sentence level with language that is indeed used in real situations that have and will be carried out in interactions.

c. Principle 3: Processes are as important as the form (the process is as important as the form of language)

The aim is to replicate the communication process as far as possible, so that the practice of language forms can occur in communicative frameworks (real forms of communication). Kith Morrow insisted that verbal interaction must be formed in the process (1) information gap, meaning that in communication there must be information that is not yet known. Another characteristic of communication participants is (2) choice, which is what choice to camouflage

The aim is to replicate the communication process as far as possible, so that the practice of language forms can occur in communicative frameworks (real forms of communication). Kith Morrow insisted that verbal interaction must be formed in the process (1) information gap, meaning that in communication there must be information that is not yet known. Other characteristics of communication participants are (2) choices, namely what choices should be conveyed and how to convey them. There is a process of not only choosing what ideas to convey at a particular moment, but also which form of language is appropriate for expressing. 
Finally, there must be (3) feedback to check whether the desired communication or interaction goal is successful.

d. Principle 4: To learn it, to do it

To gain language skills must go through practice or learning by doing.

e. Principle 5: Mistakes are not always mistakes

2. Learning Procedures

English learning procedure is a step of learning to achieve the target language competency. English learning procedures refer to the principles of communicative methodology. The game is one form of English learning procedures. The five principles of communicative methodology are followed in the game.

3. Games for Foreign Language Learning

The game gets a clear and important place in the theory of English learning based on the development of communicative competence (Maley, 1981: 137). All classrooms are not the real world in terms of certain important things. It is impossible for a real communication situation in the real world to exist in the classroom, for that game becomes important to enable a learning activity that encourages natural, creative, and or authentic language behavior. Games have clear rules as where in the real world that cannot be separated from the rules in acting speech. It must be admitted "the game itself is not the real world, but what happens in the framework offered by the game is how pure the language behavior of game participants and involves functional categories (language functions) that can be applied more broadly" (ibid).

\section{Writing Learning}

1. Writing Competence

Writing learning objectives in high school are achieving text-based writing competency. What will be examined in this study is to write a Report (natural phenomena focus on animals).

To gain genre-based writing skills, in addition to having to (1) master the vocabulary that is adequate for writing a text, students must (2) have the ability to compile text coherence (topics and text structure), and (3) be able to arrange sentences correctly (syntax) .

Referring to Curriculum 13 High School English, the elements of writing competence that must be met are.

a. The structure of the report's text includes (1) definition or classification, (2) description of each aspect. (coherence)

b. The dominant form of language (tenses) (grammar)

c. Enabling diction or vocabulary (vocabulary)

2. Writing Learning Procedures

Steps in Writing Learning in general are (1) pre-writing activities (2) jot-down (writing points to be written) (3) draft, and (4) editing. The pre-writing stage is the stage of preparation by exploring the ideas to be written, preparing the necessary vocabulary as well as detailed points related to the topic to be written. Jot-down stages to build coherence (text structure) and arrange detailed points following global coherence. Third stage, completing the draft report. The final stage is editing the article by discussing it.

3. Game before writing procedure

Writing competence includes several elements which are generally considered heavy and require sufficient concentration. To compensate for the full concentration to complete the report writing task, it needs entertaining learning procedures. The game or game is used to explore topics, ideas, relevant vocabulary in the form of interacting activities at the pre-writing stage. 
Many English educators consider gaming an effective learning procedure. First, the game is an activity that has rules, goals and elements of fun or fun (Headfield, 1990: 5). The attitude that is built through the game is relevant to the elements of writing learning where students must have discipline, must obey the rules and have goals. What is more supportive is that the fun element can be used to offset perceptions that writing is difficult. Second, "[game] increases motivation [of students], ... which contrasts with [learning styles] which are intensive [commonly used] (Haycraft, 1978: 94). Third, the game provides an opportunity to compete in a friendly, non-hostile way so that students feel comfortable and familiar with this activity, as Lee (1979: 1) said, "the essence of many games relies on outstripping, in a friendly fashion, someone else's performance or in bettering one's own.

Game before writing procedure

is a learning procedure that begins with pre-teaching games. This procedure was developed as a treatment for students to achieve the Writing Report competency.

\section{Method}

\section{A. Research design}

The design of this study is pre-test-post-test group design. Before learning to use the Game Before Writing Procedure, a pre-test is conducted. After implementing the Game Before Writing Procedure using the Nox Android Emulator, a post-test is performed.

\section{B. Population and Samples}

The population is high school students SMA Bhayangkari 10 Porong. Research samples were 39 students. The technique used is simple random sampling.

\section{Research variables}

There are three variables in this research, namely one independent variable and two dependent variables. Game before writing procedure using Nox Adroid Emulator is a free variable. While the dependent variable is the achievement of report writing competence and the level of student involvement in writing report learning.

\section{Data collection techniques}

Through tests and observations during the implementation of learning.

\section{E. Research Instruments}

Pre-test and Post-test and observation sheet.

\section{F. Data Analysis}

Using the T Test and descriptive.

\section{Findings and Discussion \\ Findings}

This study collected data from the results of the pre-test and post-test learning report writing and observations during the learning process. The following table shows the results of the TTest.

Pre-Test Post-Test

Mean 55 67,433

SD $12,61710,251$

N 3939

T test to compare the pre-test and post-test averages. From the table above, the mean difference is 12,435 . This means that Learning with Game Before Writing Procedure has an influence on the ability of Writing Report. SD scores on the smaller post-test showed significant changes. 
Basuki, Aquariza

TELL: Teaching of English Language and Literature Journal

Vol. 7, No 2, September 2019, DOI http://dx.doi.org/10.30651/tell.v7i2.3326

Test $\mathrm{T}$ value $<0.005$, Ho is rejected, which means that the use of the Nox Andoid Emulator for the application of learning before game writing procedures is effective for improving the competency of writing reports for high school students ...

Student involvement increased based on observations of more than $80 \%$ of students during the learning process actively involved in the game.

\section{Conclusion}

Based on the results of the $\mathrm{T}$ Test for the Utilization of the Nox Android Emuator in the implementation of Game Before Writing Learning Procedures, it is effective in improving report writing skills. The game encourages higher student involvement because it is fun.

\section{References}

Gagne, R. M \& Briggs, L. J. Principles of instructional design. New York: Holt, Rinehart and Winston, 1974

Headfield (1990) Intermediate Communication Games. England: Longman. Haycraft (1978) An Introduction to English Language Teaching.Malaysia: Longman.

Keith (1981) Principles of Communicative Methodology in John and Morrow (Ed)

Communication in the Classroom: Applicationa and Methods for a Communicative Approach. England: Longman Group Ltd.

Kemp, J.E \& Dayton, D.K. 1985. Planning and Producing Instructional Media. Cambridge: Harper \& roW Publisher, New York.Nugent, G. C. (1982). Pictures, audio, and print: Symbolic representation

Kemp, J.E \& Dayton, D.K. 1985. Planning and Producing Instructional Media. Cambridge: Harper \& roW Publisher, New York.Nugent, G. C. (1982). Pictures, audio, and print: Symbolic representation and effect on learning. Educational Communication and Technology Journal, 30, 163-174.

Lee (1978) Language Teaching Games and Contests. ( $\left.2^{\mathrm{d}} \mathrm{ed}\right)$. Oxford:Oxford University Press.

Maley (1981) Games and Problem Solving in John and Morrow (Ed) Communication in the Classroom: Applicationa and Methods for a Communicative Approach. England: Longman Group Ltd.

Hamalik, O. (1986). Appropriate Learning Media. Alumni

Levie, W. H., \& Lentz, R. (1982). Effects of text illustrations: A review of research. Educational Communication and Technology Journal, 30, 195-232.

Paivio,A. (1991). Dual coding theory: Retrospect and current status. Canadian Journal of Psychology

Pizam, A. and Ellis, T. (1999), Customer satisfaction and its measurement in hospitality enterprises,International Journal of Contemporary Hospitality Management, Vol. 11(7), pp. 326-339. Retrieved from https://www.bignox.com/blog/how-to-usekeyboard-mapping-to-play-android-gameson-pc/ accessed on 24 July 2015 Retrieved from http://noxandroidemulator.com/ accessed on 24 July 2015 